\title{
Implementation of Ultra-modified Symmetric Sequence Algorithm for Space Vector Modulation of Matrix Converter
}

\author{
Kotb B. Tawfiq, A. S. Mansour, E. E. EL-Kholy
}

Department of Electrical Engineering, Faculty of Engineering, Menoufia University, Egypt

\begin{tabular}{ll}
\hline \hline Article Info & ABSTRACT \\
\cline { 2 - 3 } Article history: & $\begin{array}{l}\text { This paper proposes an ultra-modified symmetric sequence algoritm of space } \\
\text { vector modulation of matrix converter. The ultra-modified technique } \\
\text { improves the drawbacks of the modified one where it provides a reduction of } \\
\text { Received Jun 9, 2018 } \\
\text { Revised Aug 18, } 2018\end{array}$ \\
$\begin{array}{l}\text { Accepted Nov 20, } 2018 \\
\text { Some of the advantages of matrix converter are introduced in this paper. } \\
\text { These advantages represented in the output frequency of matrix converter } \\
\text { which may be greater than input frequency, controlling rms value of the } \\
\text { output voltage and the ability to control the input displacement factor.At the } \\
\text { end of this paper simulation and experimental results are introduced which } \\
\text { give a presice proof to the proposed algorithms. }\end{array}$
\end{tabular}

Copyright $\odot 2018$ Institute of Advanced Engineering and Science. All rights reserved.

Corresponding Author:

Kotb B. Tawfiq,

Department of Electrical Engineering,

Faculty of Engineering, Menoufia University, Egypt.

Email: kotb.bassem@sh-eng.menofia.edu.eg

\section{INTRODUCTION}

The bold feature of Matrix Converter (MC) over rectifier-inverter converter is that the AC can be directly converted to AC with different voltage rms value and different frequency without using any DC link, so $\mathrm{MC}$ can be considered an emerging alternative to the conventional rectifier-inverter converter. Independent control on the output voltage magnitude and frequency can be provided by utilizing a MC. In addition to control the phase angle between input voltage and input current and unity input displacement factor can be achieved. However, this topology does not take its proper place in the industry so far. Because of the potential commutation problems, it requires a complex control and snubber circuits, in addition to inaccessibility of bi-directional switches, and low voltage gain [1], [2]. This paper introduces a static R-L load controlled by using a MC as shown in Figure 1. MC is controlled by using indirect space vector modulation. There are many space vector modulation algorithms. In this paper an ultra-modified symmetric sequence space vector modulation algorithm is proposed. This method has lower THD of voltage compared to conventionaland modified symmetric sequence method, so the size of the required filter is reduced. First, a short description of MC is introduced. Secondly indirect space vector control of MC is presented showing how to transform from indirect converter to direct one [3], [4]. MC is used to control load voltage and frequency. Third the ultra-modified symmetric sequence algorithm is proposed. Fourth simulation and experimental results for different operating points are displayed.

\section{MATRIX CONVERTER}

$\mathrm{MC}$ is an AC-AC converter that consists of nine-bidirectional switches which provides a direct connection between the three-phase input voltage with the load without utilizing any dc link so MC can be manufactured in a simple and compact form. Matrix converter has the ability of bi-directional power flow, 
unity input displacement factor can be provided [5]. Also, it has minimal energy storage requirements, which permits to dispose of massive and lifetime-constrained capacitor, but MC does not take its proper place in the industry as it has some disadvantages. It has limited input output voltage transfer ratio to 0.866 for sinusoidal input and output waveforms [6], [7]. Because of the lack of switches that allow to the current to flow in both directions, some MC types need more number of switches compared to conventional rectifier-inverter type. Input filters are required to reduce the high frequency harmonics and clamping circuit are needed to protect switches from over voltages due to energy stored in inductive loads. In 1976 Gigi and Pelly introduce the first principle of a MC [8]. The first mathematical form of MC was introduced in 1980 by Venturini and switches are the primary disadvantage of this converter [9].

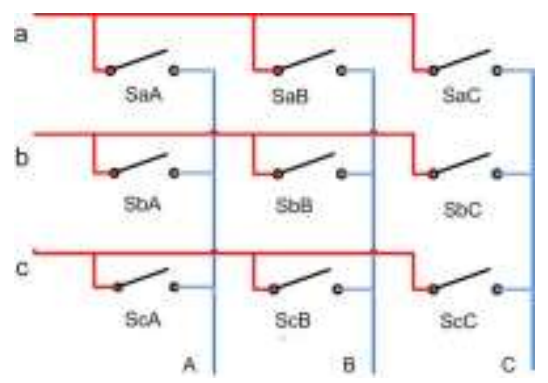

Figure 1. Direct MC

\subsection{Construction of matrix converter}

The main structures of MC consists of matrix switches, input filter and clamping circuit as shown in Figure 2 [10].

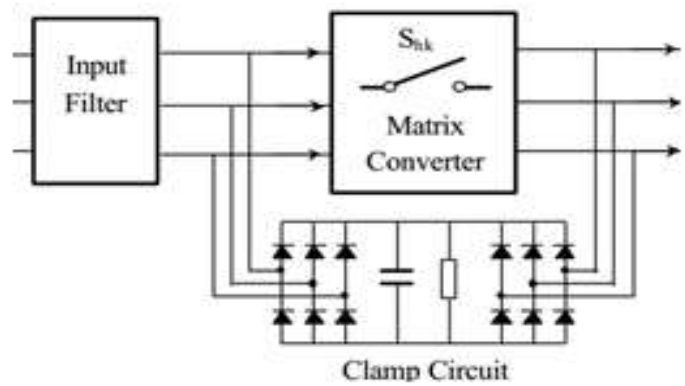

Figure 2. The main structure of MC

\subsubsection{Matrix switches}

Matrix converter requires a bi-directional switch, bi-directional switch has the ability to connect the current in both directions, but these switches are not available in our markets so far. Thus conventional unidirectional can be used to obtain bi-directional switches as shown in Figure 3. The bi-direction switch used in this proto type is that shown in Figure 3(a) [11].

\subsubsection{Diode bridge with a single switch}

This switch consists of a four ultra-fast diodes with a controllable uni-directional switch as shown in Figure 3(a). The main advantage of this switch is that it has a simple construction and it requires only IGBT. The disadvantage of this switch it requires 36 ultra-fast diodes and nine isolated power supply as shown in Table 1 [11].

\subsubsection{Common emitter Bi-directional switch}

This switch consists of two ultra-fast diodes with two controllable uni-directional switches as shown in Figure 3(b). The main advantage of this switch is that it can control the current through switch. The disadvantage of this switch it requires more gate drives power supplies and more IGBTs as shown in Table 1 [11]. 


\subsubsection{Common collector Bi-directional switch}

This switch consists of a two ultra-fast diode with two controllable uni-directional switches (IGBT) as shown in Figure 3(c). This switch has the same advantage of the common emitter one but this switch requires only six isolated gate power supplies. The disadvantage of this switch compared to diode bridge with a single switch, it requires more IGBTs as shown in. Table 1 [11].

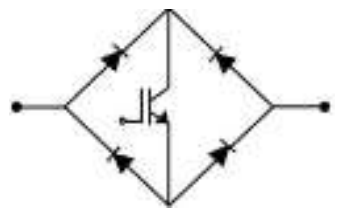

(a)

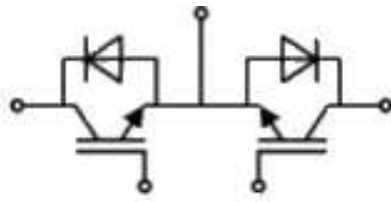

(b)

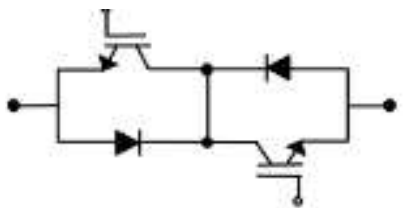

(c)

Figure 3(a). Diode bridge with single IGBT, (b) Common emitter bi-directional switch,(c) Common collector bi-directional switch

Table 1 the Difference Between Bi-directional Switches

\begin{tabular}{ccccc}
\hline AC-Switch & MOSFET & Diode & Isolated gate supplies & Gate signal \\
\hline Diode bridge with single Switch & 9 & 36 & 9 & 9 \\
Common Emitter bi-directional switch & 18 & 18 & 9 & 18 \\
Common Collector bi-directional Switch & 18 & 18 & 6 & 18 \\
\hline
\end{tabular}

\subsubsection{Input filter}

As all power electronic-based converters, MC injects harmonics into the grid, which affects other equipment connected to the same system. The power converter must meet the requirements given in IEEE 519. This standard refers to the allowable injected harmonic contents into the electrical network. Therefore, the matrix converter requires a suitable input filter to reduce these harmonic components. In order to reduce the current harmonics in the supply, an LC low-pass filter can be included, as shown in Figure 4(a). The input filter has to meet the following main requirements. High efficiency, small size and low cost and very small voltage drop across the filter inductance [12].

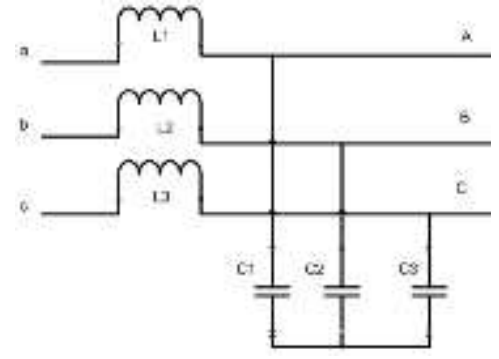

(a)

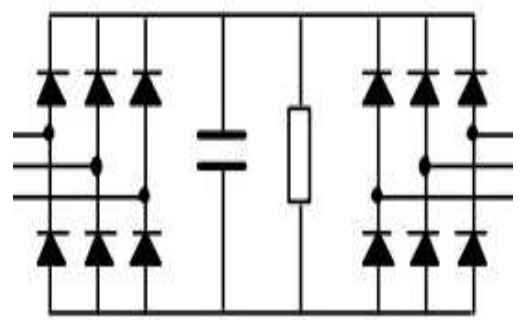

(b)

Figure 4. (a) Input filter, (b) Clamp circuit

\subsubsection{Clamping circuit}

The clamp circuit protects matrix switches from over voltages Figure 4(b) shows clamp circuit used to protect matrix switches. When all switches of a matrix converter are turned off the inductive load has to discharge the energy stored in it without making any dangerous over voltages. Therefore, the energy stored in the inductive loads can be discharged through clamp circuit [12].

\subsection{Control of matrix converter}

MC consists of nine-bidirectional switches which allow all input lines to connect to all output lines. If the switches of $\mathrm{MC}$ are arranged as shown on Figure 5 the power on the input of the matrix converter must 
be equal to the output power as there is no any energy storage element. Indirect space vector control is the control strategy used in this paper.

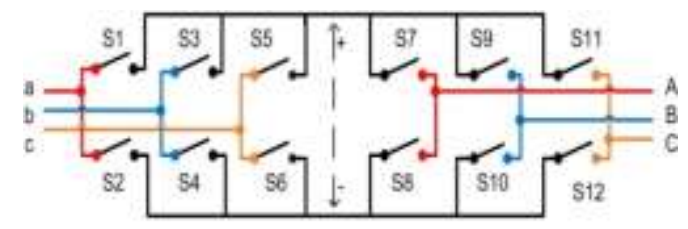

Figure 5. Indirect matrix converter

\subsubsection{Transformation form indirect $\mathrm{MC}$ to direct $\mathrm{MC}$}

Indirect space vector control deals with $\mathrm{MC}$ as a rectifier-inverter combination with virtual dc link as shown in Figure 5. Indirect MC consists of two stages, first stage is rectifier based on switches S1-S6, second stage is inverter, which has a standard three phases voltage source topology based on six switches S7-S12 [13].

$$
\begin{aligned}
& V_{D C}=E * V_{a b c} \quad, \quad V_{A B C}=N * V_{D C}, \quad V_{A B C}=\mathrm{N} * \mathrm{E} * V_{a b c} \quad, \quad \mathrm{~K}=\mathrm{N} * \mathrm{E} \\
& E=\left[\begin{array}{lll}
S_{1} & S_{3} & S_{5} \\
S_{2} & S_{4} & S_{6}
\end{array}\right], \quad N=\left[\begin{array}{ll}
S_{7} & S_{8} \\
S_{9} & S_{10} \\
S_{11} & S_{12}
\end{array}\right], \quad K=\left[\begin{array}{lll}
S_{a A} & S_{b A} & S_{c A} \\
S_{a B} & S_{b B} & S_{c B} \\
S_{a C} & S_{b C} & S_{c C}
\end{array}\right] \\
& {\left[\begin{array}{lll}
S_{a A} & S_{b A} & S_{c A} \\
S_{a B} & S_{b B} & S_{c B} \\
S_{a C} & S_{b C} & S_{c C}
\end{array}\right]=\left[\begin{array}{ll}
S_{7} & S_{8} \\
S_{9} & S_{10} \\
S_{11} & S_{12}
\end{array}\right]\left[\begin{array}{lll}
S_{1} & S_{3} & S_{5} \\
S_{2} & S_{4} & S_{6}
\end{array}\right]}
\end{aligned}
$$

Where the inverter transfer function is represented by a matrix $\mathrm{N}$, transfer function of the rectifier is represented by a matrix E and $\mathrm{K}$ represent transfer function of MC [14]. This strategy deals with MC as a cascaded rectifier-inverter. Therefore, space vector of the inverter output voltage and space vector of rectifier input current can be decoupled to control direct MC. As shown in (4), the output phases can be compounded by the product and sum of input phases through rectifier and inverter switches $S_{1}-S_{6}$ and $S_{7}-S_{12}$ respectively. The first row of the matrix in (5) shows how to obtain output phase A from input phases a, b and $\mathrm{c}$ for direct MC using Indirect Space Vector Modulation (ISVM) and this can be illustrated again in graphical viewpoint as in Figure 6 [11], [12].

$$
\begin{aligned}
& {\left[\begin{array}{l}
V_{A} \\
V_{B} \\
V_{C}
\end{array}\right]=\left[\begin{array}{ll}
S_{7} & S_{8} \\
S_{9} & S_{10} \\
S_{11} & S_{12}
\end{array}\right]\left[\begin{array}{lll}
S_{1} & S_{3} & S_{5} \\
S_{2} & S_{4} & S_{6}
\end{array}\right]\left[\begin{array}{l}
v_{a} \\
v_{b} \\
v_{c}
\end{array}\right]} \\
& {\left[\begin{array}{l}
V_{A} \\
V_{B} \\
V_{C}
\end{array}\right]=\left[\begin{array}{lll}
S_{7} S_{1}+S_{8} S_{2} & S_{7} S_{3}+S_{8} S_{4} & S_{7} S_{5}+S_{8} S_{6} \\
S_{9} S_{1}+S_{10} S_{2} & S_{9} S_{3}+S_{10} S_{4} & S_{9} S_{5}+S_{10} S_{6} \\
S_{11} S_{1}+S_{12} S_{2} & S_{11} S_{3}+S_{12} S_{4} & S_{11} S_{5}+S_{12} S_{6}
\end{array}\right] *\left[\begin{array}{l}
v_{a} \\
v_{b} \\
v_{c}
\end{array}\right]}
\end{aligned}
$$

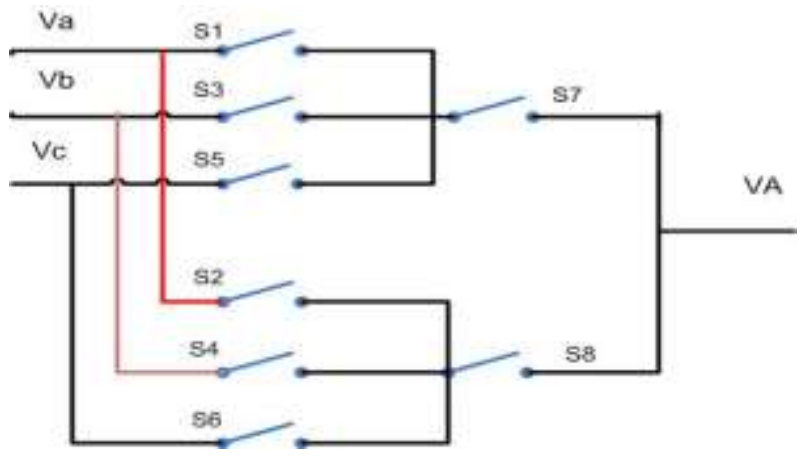

Figure 6. Transformation from indirect matrix converter to direct one in phase A 


\subsubsection{Current source}

The current source rectifier consists of six switches S1-S6, as shown in Figure 7. The rectifier has to generate constant dc voltage from three phase input voltage. The virtual dc link voltage and input currents can be calculated from the rectifier transfer function $\mathrm{E}$ as follows

$$
\begin{aligned}
& {\left[\begin{array}{c}
V_{D C}^{+} \\
V_{D C}^{-}
\end{array}\right]=\left[\begin{array}{lll}
S_{1} & S_{3} & S_{5} \\
S_{2} & S_{4} & S_{6}
\end{array}\right]\left[\begin{array}{l}
V_{a} \\
V_{b} \\
V_{c}
\end{array}\right]} \\
& {\left[\begin{array}{l}
I_{a} \\
I_{b} \\
I_{c}
\end{array}\right]=\left[\begin{array}{ll}
S_{1} & S_{2} \\
S_{3} & S_{4} \\
S_{5} & S_{6}
\end{array}\right]^{T}\left[\begin{array}{l}
I_{p} \\
I_{n}
\end{array}\right]}
\end{aligned}
$$

The input current space vector $\mathrm{I}_{\mathrm{IN}}$ can be expressed as follows

$$
I_{I N}=\frac{2}{3}\left(I_{a}+a \cdot I_{b}+a^{2} \cdot I_{c}\right)
$$

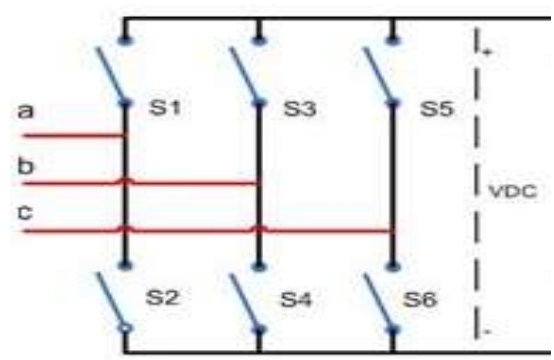

Figure 7. Current source rectifier

For virtual rectifier, there is allowed nine switching combinations to avoid an open circuit in rectifier. These nine combinations are divided into six active nonzero input current vectors $I_{1}-I_{6}$ and three zero input current vectors $I_{0}$ as shown in Figure 8(a). The current space vector state $I_{1}(a b)$ means that input phase $a$ is connected to the positive terminal of the virtual dc link (VDC+) and input phase $b$ is connected to the negative terminal (VDC-). Figure 8(a) shows the configuration of the discrete seven space vectors of the input current in a hexagon in a complex plane and the reference input current vector $\mathrm{I}_{\text {IN }}^{*}$ within a sector of the input current hexagon [12]. The $\mathrm{I}_{\mathrm{IN}}$ can be obtained by impressing the adjacent active vectors $\mathrm{I}_{\gamma}$ and $\mathrm{I}_{\delta}$ with the duty cycles $\mathrm{d}_{\gamma}$ and $\mathrm{d}_{\delta}$, respectively, as shown in Figure 8(b). By using the current-time product sum of the adjacent active vectors, the reference input vector can be expressed as follows

$$
I_{I N}^{*}=d_{\gamma} I_{\gamma}+d_{\delta} I_{\delta}+d_{o c} I_{0}
$$

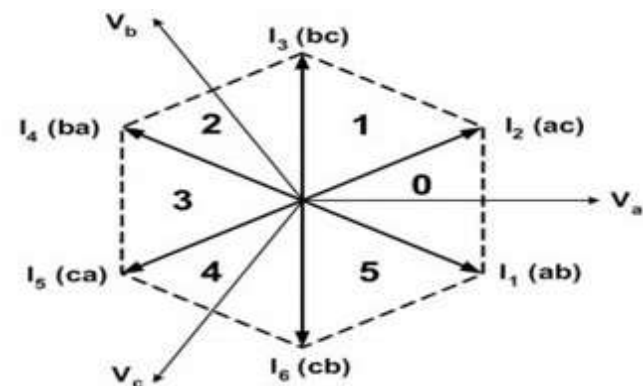

(a)

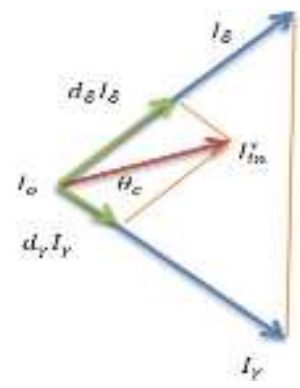

(b)

Figure 8. (a) Space vector of current source rectifier, (b) Composition of the reference input current 
The active vectors duty cycle can be written as :-

$$
\begin{aligned}
& d_{\gamma}=m_{c} \cdot \sin \left(\frac{\pi}{3}-\theta_{c}\right) \\
& d_{\delta}=m_{c} \cdot \sin \left(\theta_{c}\right) \\
& d_{0 c}=1-\left(d_{\gamma}+d_{\delta}\right)
\end{aligned}
$$

Where, $\theta_{c}$ represent the angle of the reference input current vector within the sector of the hexagon. The $\mathrm{m}_{\mathrm{c}}$ is the current modulation index and define such as;

$$
m_{c}=\frac{I_{I N}^{*}}{I_{D C}}
$$

\subsubsection{Voltage source inverter}

The Voltage Source Inverter (VSI) consists of six switches $\mathrm{S}_{7}-\mathrm{S}_{12}$ as shown in Figure 9. VSI has to generate three-phase output voltages from constant virtual DC input voltage. The output voltage can be represented as a function of DC input voltage and transfer function of the inverter as in Equation (14). The DC link current can be derived by using the transposed of transfer function of the inverter as in Equation (15)

$$
\begin{aligned}
& {\left[\begin{array}{l}
V_{A} \\
V_{B} \\
V_{C}
\end{array}\right]=\left[\begin{array}{ll}
S_{7} & S_{8} \\
S_{9} & S_{10} \\
S_{11} & S_{12}
\end{array}\right]\left[\begin{array}{c}
\frac{V_{D C}}{2} \\
\frac{-V_{D C}}{2}
\end{array}\right]} \\
& {\left[\begin{array}{l}
V_{A} \\
V_{B} \\
V_{C}
\end{array}\right]=\left[\begin{array}{ll}
S_{7} & S_{8} \\
S_{9} & S_{10} \\
S_{11} & S_{12}
\end{array}\right]\left[\begin{array}{c}
\frac{V_{D C}}{2} \\
\frac{-V_{D C}}{2}
\end{array}\right]}
\end{aligned}
$$

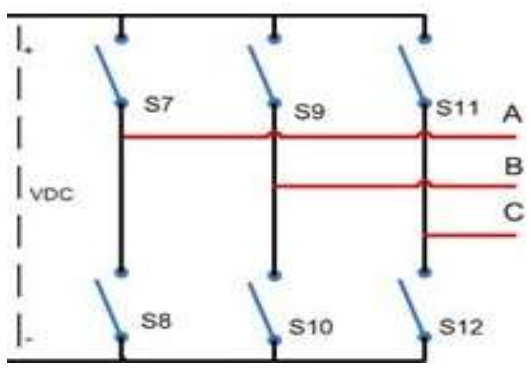

Figure 9. Voltage source inverter

The output voltage space vector $\mathrm{V}_{\text {out }}$ can be expressed as follows:

$$
\mathrm{V}_{\text {out }}=\frac{2}{3}\left(\mathrm{~V}_{\mathrm{A}}+\mathrm{a} \cdot \mathrm{V}_{\mathrm{B}}+\mathrm{a}^{2} \cdot \mathrm{V}_{\mathrm{C}}\right), \mathrm{a}=1 * \mathrm{e}^{\mathrm{j} 120}
$$

The switches of the inverter have only eight allowed combinations, because the output must not be short though three half bridges and the load must not be opened at any instant. These eight permitted combinations can be classified into six active nonzero output voltage vectors $V_{1}-V_{6}$ and two zero output voltage vectors $V_{z}$. The voltage space vector $V_{1}(100)$ means that the output phase $V_{A}$ is connected to positive terminal of the virtual dc link $\left(\mathrm{V}_{\mathrm{DC}+}\right)$ and the phases $\mathrm{V}_{\mathrm{B}}, \mathrm{V}_{\mathrm{C}}$ are connected to negative terminal $\left(\mathrm{V}_{\mathrm{DC}-}\right)$. Figure 10(a) shows the configuration of the discrete seven space vectors of the output voltage in a hexagon in a complex plane. The reference output voltage $V_{O}^{*}$ can be obtained by a vector sum out of seven discrete voltage vectors, $V_{1}-V_{6}$ and $V_{z}$. This hexagon can be divided into six sectors. The duty cycles $d_{\alpha}$ and $d_{\beta}$ of active vectors $V_{\alpha}$ and $V_{\beta}$, respectively, for the reference voltage vector $V_{O}^{*}$ within a sector of the voltage hexagon can be derived from Figure 10(b) [15]. 


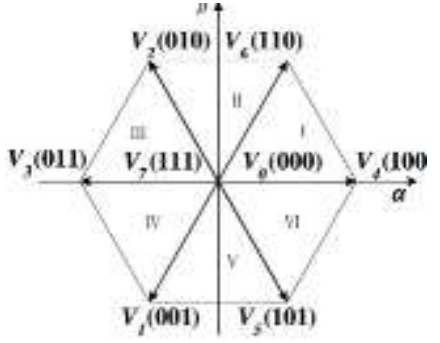

(a)

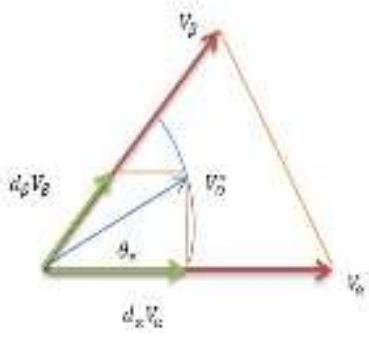

(b)

Figure 10. (a) Hexagon of inverter voltage (b) Composition of the reference output voltage vector

$$
\begin{aligned}
& \mathrm{V}_{\mathrm{o}}^{*}=\mathrm{d}_{\alpha} \mathrm{V}_{\alpha}+\mathrm{d}_{\beta} \mathrm{V}_{\beta}+\mathrm{d}_{\mathrm{z}} \mathrm{V}_{\mathrm{z}} \\
& \mathrm{d}_{\alpha}=\frac{\mathrm{T}_{\alpha}}{\mathrm{T}_{\mathrm{s}}}=\mathrm{m}_{\mathrm{v}} \cdot \sin \left(\frac{\pi}{3}-\theta_{\mathrm{v}}\right) \\
& \mathrm{d}_{\beta}=\frac{\mathrm{T}_{\beta}}{\mathrm{T}_{\mathrm{s}}}=\mathrm{m}_{\mathrm{v}} \cdot \sin \left(\theta_{\mathrm{v}}\right) \\
& \mathrm{d}_{\mathrm{z}}=\frac{\mathrm{T}_{\mathrm{z}}}{\mathrm{T}_{\mathrm{s}}}=1-\left(\mathrm{d}_{\alpha}+\mathrm{d}_{\beta}\right)
\end{aligned}
$$

Where, $T_{\alpha}, T_{\beta}$ and $T_{z}$ are the total duration times of the vectors $V_{\alpha}, V_{\beta}$ and $V_{z}$ respectively, and $\theta_{v}$ indicates the angle of the reference output voltage vector within the sector of the hexagon. The $m_{v}$ is the modulation index of the output voltage and define such as;

$$
m_{v}=\frac{\sqrt{3} v_{o, \max }}{V_{D C}}
$$

\section{SYMMETRIC SEQUENCE ALGORITHM}

This section proposes a modified symmetric sequence algorithm for space vector modulation. The proposed algorithm reduces THD of the output voltage. When the desired output voltage vector of the inverter lies in sector 1 as shown in Figure 10(b). The inverter switches 『 $S \rrbracket_{-} 7$ 『- S \_12 doesn't have a state represent this position, so this position can be represented by adjacent vector $\left[\mathrm{V} \rrbracket \_\alpha, \mathrm{V} \_\beta\right.$ [and $\mathrm{V} \rrbracket \_z w i t h$ duty cycle d_ $\alpha,\left[\mathrm{d} \_\beta\right.$ and $\left.\left.\mathrm{d}\right)\right] \_$. The main distinction between PWM algorithms that utilize adjacent vectors is zero vector selection, sequence in which the adjacent vectors are applied and splitting of the duty cycle of each adjacent vector [11], [12].

\subsection{Conventional symmetric sequenc algorithm}

There are many SVM algorithms; one of them is symmetric sequence algorithm that has low THD as shown in Figure 11(a). During each switching time $T_{s}$ the duty cycles of each vector $V_{\alpha}, V_{\beta}$ and $V_{z}$ $\left(d_{\alpha}, d_{\beta}\right.$ and $\left.d_{z}\right)$ is calculated. In the conventional symmetric sequence algorithm the duty cycle of vector $V_{\alpha}$ $\left(d_{\alpha}\right)$ is divided to two equal period, $d_{\beta}$ also and $d_{z}$ is divided to three periods $\frac{d_{z}}{2}, \frac{d_{z}}{4}$ and $\frac{d_{z}}{4}$. The sequence in this method is $\mathrm{V}_{\mathrm{z}}-\mathrm{V}_{\alpha}-\mathrm{V}_{\beta}-\mathrm{V}_{\mathrm{z}}-\mathrm{V}_{\beta}-\mathrm{V}_{\alpha}-\mathrm{V}_{\mathrm{z}}[11]$.

\subsection{Modified symmetric sequenc algorithm}

In [12] a modified symmetric sequence algorithm is proposed, the modification in this algorithm is the sequence in which the vectors are applied and the number of division of each duty cycle for each vector. In the modified algorithm the duty cycle of $V_{\alpha}\left(d_{\alpha}\right)$ is divided to four equal periods, $d_{\beta}$ also and $d_{z}$ is divided to five periods $\frac{d_{\mathrm{z}}}{4}, \frac{\mathrm{d}_{\mathrm{z}}}{4}, \frac{\mathrm{d}_{\mathrm{z}}}{4}, \frac{\mathrm{d}_{\mathrm{z}}}{8}$ and $\frac{\mathrm{d}_{\mathrm{z}}}{8}$. The sequence in the proposed algorithm is as follow $\mathrm{V}_{\mathrm{z}}-\mathrm{V}_{\alpha}-$ $\mathrm{V}_{\beta}-\mathrm{V}_{\mathrm{z}}-\mathrm{V}_{\alpha}-\mathrm{V}_{\beta}-\mathrm{V}_{\mathrm{z}}-\mathrm{V}_{\beta}-\mathrm{V}_{\alpha}-\mathrm{V}_{\mathrm{z}}-\mathrm{V}_{\beta}-\mathrm{V}_{\alpha}-\mathrm{V}_{\mathrm{z}}$ as shown in Figure 11(b).

\subsection{Ultra-modified symmetric sequenc algorithm}

This paper proposes an ultra-modified symmetric sequence algorithm, sothat to overcome the drawback of the modified algorithm. In the ultra-modified algorithm the duty cycle of $V_{\alpha}\left(d_{\alpha}\right)$ is divided to 
six un equal periods $\frac{\mathrm{d}_{\alpha}}{4}, \frac{\mathrm{d}_{\alpha}}{4}, \frac{\mathrm{d}_{\alpha}}{8}, \frac{\mathrm{d}_{\alpha}}{8}, \frac{\mathrm{d}_{\alpha}}{8}$ and $\frac{\mathrm{d}_{\alpha}}{8}, \mathrm{~d}_{\beta}$ also and $\mathrm{d}_{\mathrm{z}}$ is divided to seven un equal periods $\frac{\mathrm{d}_{\mathrm{z}}}{4}, \frac{\mathrm{d}_{\mathrm{z}}}{8}, \frac{\mathrm{d}_{\mathrm{z}}}{8}, \frac{\mathrm{d}_{\mathrm{z}}}{8}, \frac{\mathrm{d}_{\mathrm{z}}}{8}, \frac{\mathrm{d}_{\mathrm{z}}}{8}$ and $\frac{\mathrm{d}_{\mathrm{z}}}{8}$. The sequence in the proposed algorithm is as follows $\mathrm{V}_{\mathrm{z}}-\mathrm{V}_{\alpha}-$ $\mathrm{V}_{\beta}-\mathrm{V}_{\mathrm{z}}-\mathrm{V}_{\alpha}-\mathrm{V}_{\beta}-\mathrm{V}_{\mathrm{z}}-\mathrm{V}_{\alpha}-\mathrm{V}_{\beta}-\mathrm{V}_{\mathrm{z}}-\mathrm{V}_{\beta}-\mathrm{V}_{\alpha}-\mathrm{V}_{\mathrm{z}}-\mathrm{V}_{\beta}-\mathrm{V}_{\alpha}-\mathrm{V}_{\mathrm{z}}-\mathrm{V}_{\beta}-\mathrm{V}_{\alpha}-\mathrm{V}_{\mathrm{z}}$ as in Figure 11(c).

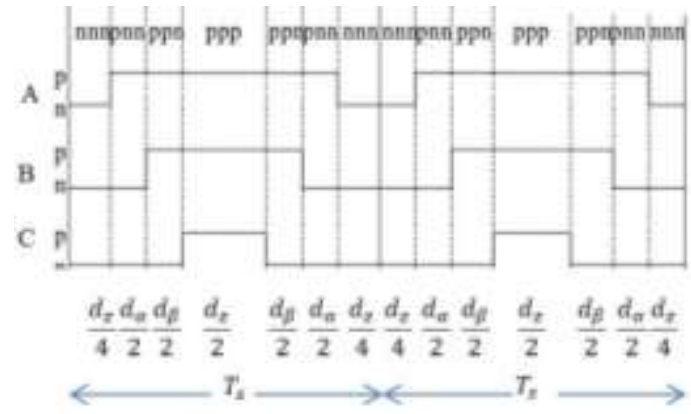

(a)

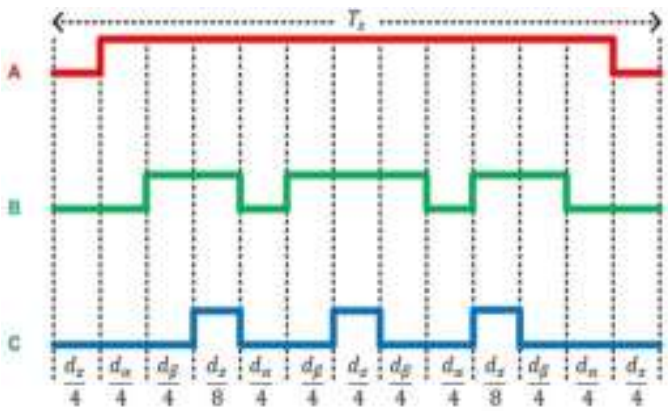

(b)

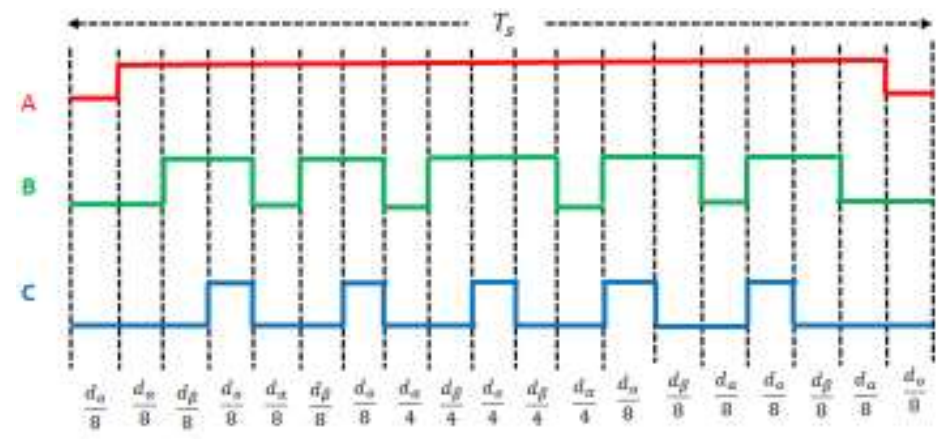

(c)

Figure 11(a). Conventional symmetric sequence algorithm, (b) Modified symmetric sequence algorithm,

(c) Ultra-modified symmetric sequence algorithm

\subsection{Implementation of ultra-modified symmetric sequence algorithm}

This part introduces how to implement SVM of VSI with ultra-modified symmetric sequence algorithm by using MATLAB Simulink. Figure 12(a) show how to transform the reference output voltage into vector angle and vector amplitude. By using the angle of the reference output voltage we can know number of sector in which the reference output voltage is located. If the reference output voltage vector of the VSI locates in sector 1 as shown in Figure 12(a) the inverter switches $\left[S \rrbracket_{-} 7\right.$ [- S】_12 doesn't have a state

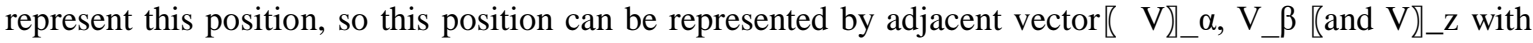
dutycycle d_ $\alpha,\left(d \_\beta\right.$ and $\left.d\right) \_z$. After calculating the duty cycles of each adjacent vectors, every one ask himself how to deal with adjacent vector and the sequence in which these duty cycles are applied to VSI. The answer to this question is modified symmetric sequence algorithm. Figure 12(b) shows the trend of implementation ultra-modified symmetric sequence algorithm in MATLAB Simulink. The first step after calculating duty cycles for each adjacent vector in modified symmetric sequence algorithm is to apply the zero vectors for a time equal to one-fourth its period. This can be achieved by comparing the one-eighty of zero vectors duty cycle with a ramp signal of a switching time equal to $2 \mu \mathrm{s}$ as shown in Figure $12(\mathrm{~b})$. The second step is to apply the first vectors for a time equal to one- eighty its period. This can be achieved by comparing the ramp signal with two signals as shown in Figure 12(b). The third step is to apply the second vectors for a time equal to one- eighty its period. This can be achieved by comparing the ramp signal with two signals as shown in Figure 12(b) and so on. 


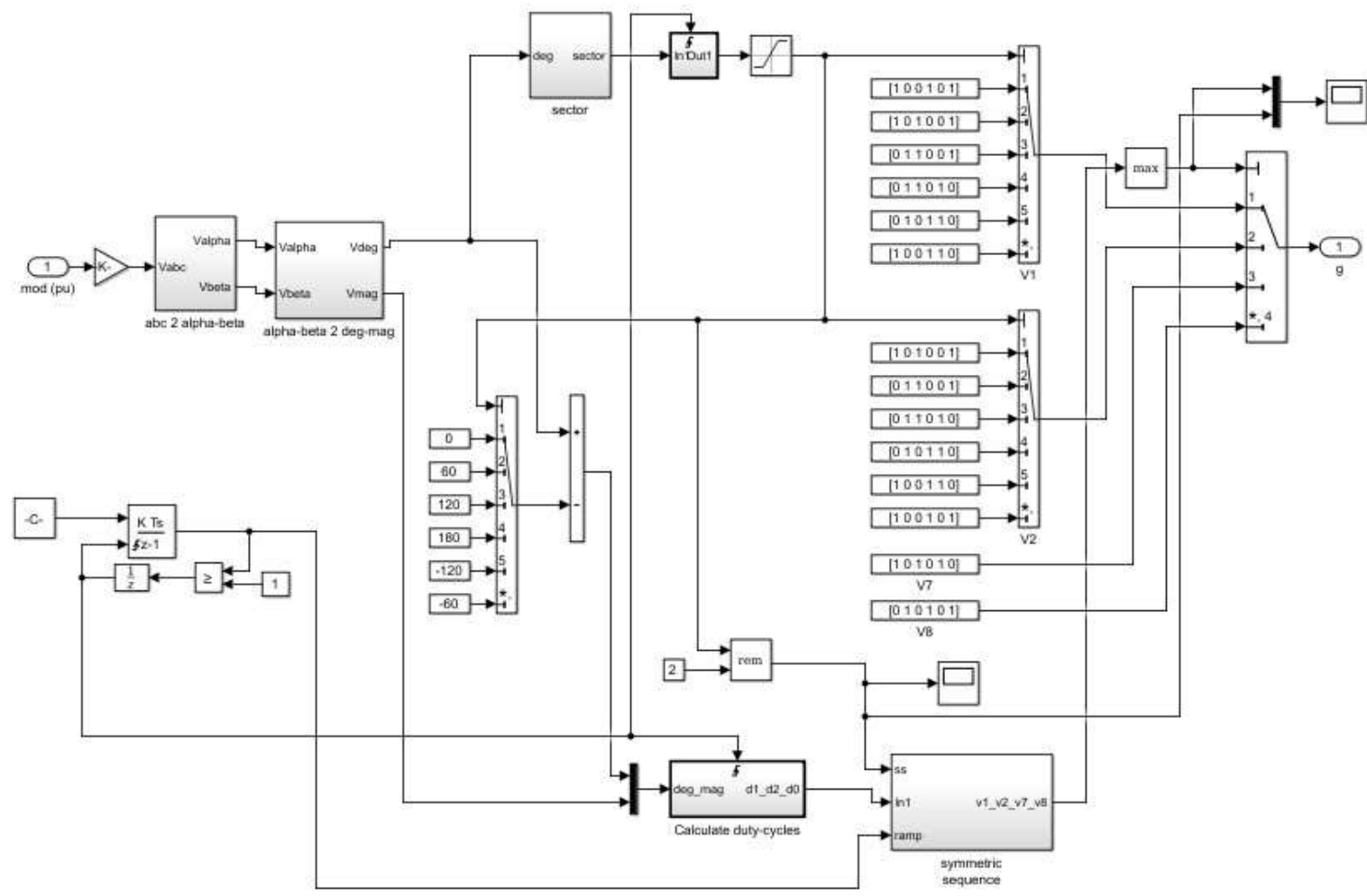

(a)

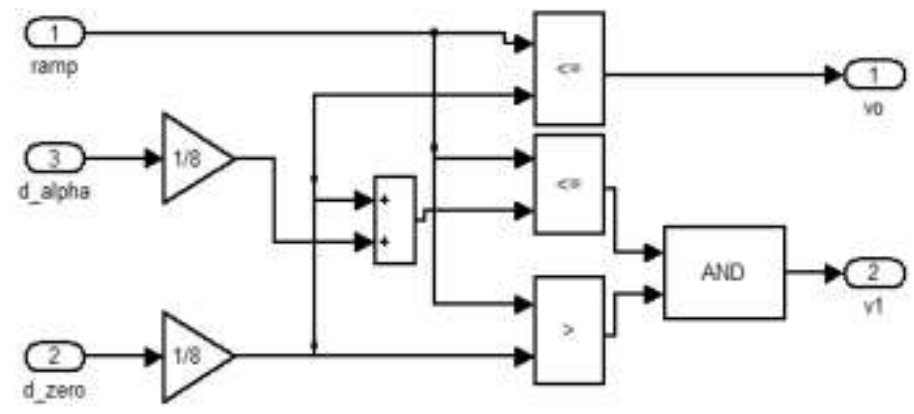

(b)

Figure 12. Implementation of the ultra-modified symmetric sequence algorithm

\section{SIMULATION RESULTS}

Simulations were done using MATLAB/Simulink software package. The simulation results for a MC interfaced $50 \mathrm{~Hz}$ three-phase supply with an isolated $\mathrm{R}-\mathrm{L}$ load $(\mathrm{R}=144 \Omega, \mathrm{L}=0.25 \mathrm{H})$ will be presented with switching time $=2 \mathrm{e}-6 \mathrm{sec}$. The ultra-modified symmetric sequence algorithm is used with indirect space vector to control MC. The modified algorithm reduces the THD for the output voltage as shown in Figure 14 also THD for output voltage with conventional symmetric sequence is shown in Figure 13(a). The simulation results showed that the THD of output voltage is reduced with the modified algorithm. The modified method decreases the THD of the output voltage so decrease cost and size of the required filter but this amethod increases THD of the output current as shown in in Figure 14(b). The proposed method decreases the THD of the output voltage and current as shown in in Figure 15. Figure 16 shows input displacement factor control, Figure 16(a) shows unity input displacement factor, Figure 16(b) shows input displacement factor with displacement factor angle equal to $20 \Omega \wedge$ o. Other simulation results that show unlimited output frequency of MC are showed where, Figure 17 shows $100 \mathrm{~Hz}$ output frequency, Figure 18 shows $12.5 \mathrm{~Hz}$ output frequency. 


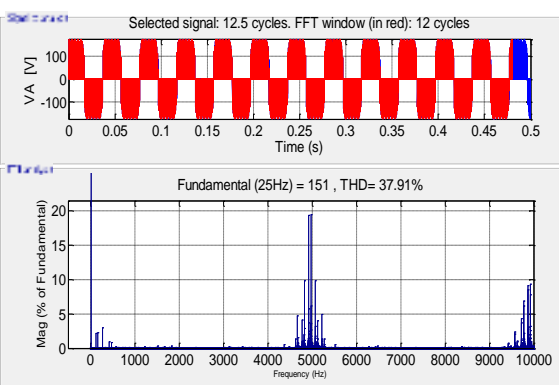

(a)

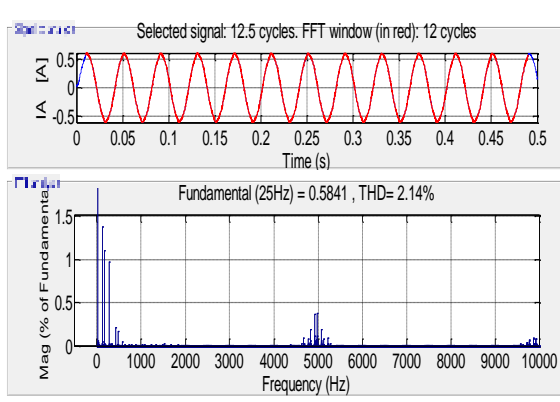

(b)

Figure 13. Simulation result of THD for $25 \mathrm{~Hz}$ (a) Output voltage,(b) Output current for conventional symmetric sequence algorithm

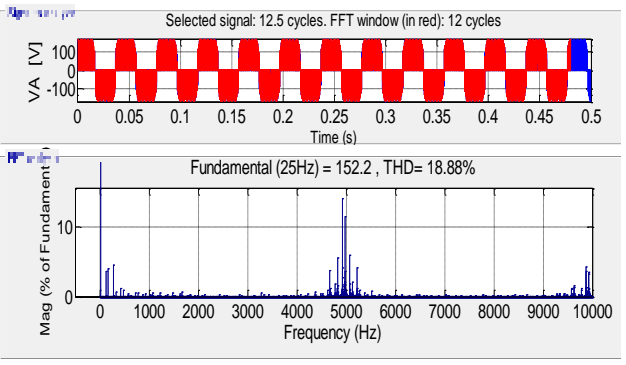

(a)

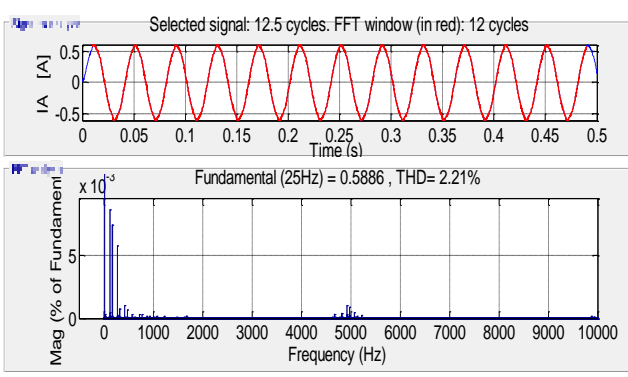

(b)

Figure 14. Simulation RESULT of THD for $25 \mathrm{~Hz}$ (a) Output voltage,(b) Output current for modified symmetric sequence algorithm

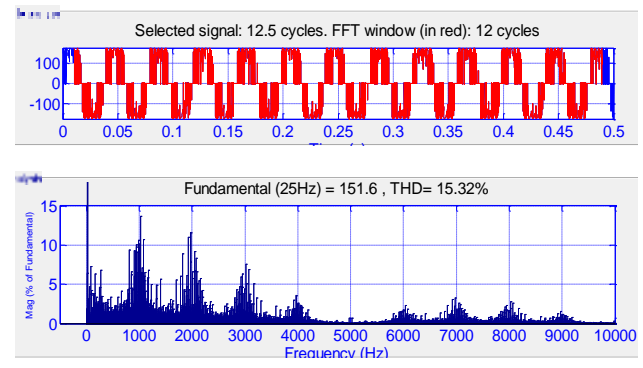

(a)

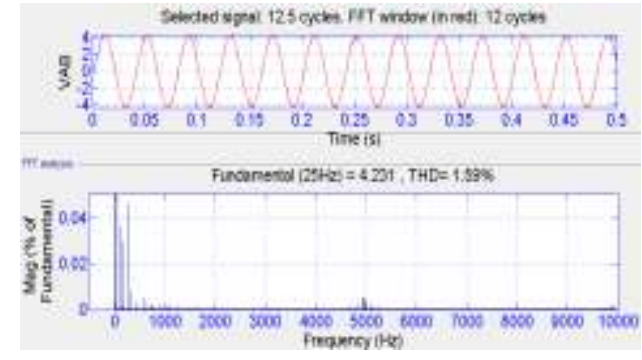

(b)

Figure 15. Simulation result of THD for $25 \mathrm{~Hz}$ (a) Output voltage,(b) Output current for ultra-modified symmetric sequence algorithm

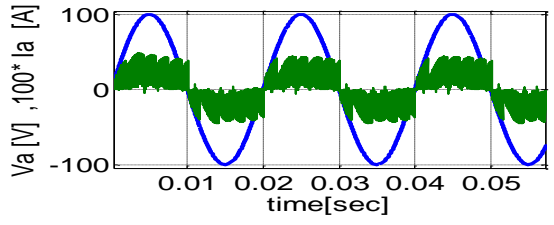

(a)

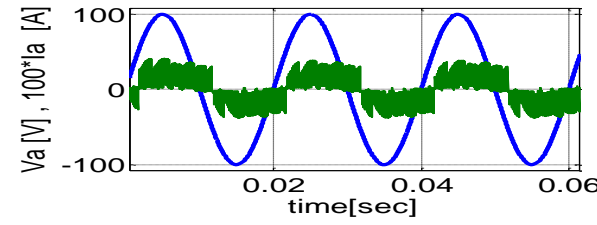

(b)

Figure 16. Control of displacement factor (a) Unity input displacement factor (b)Displacement factor of angle $20^{\circ}$ 


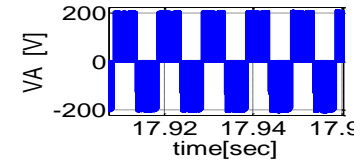

(a)

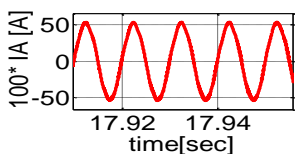

(b)

Figure 17. Simulation results for $100 \mathrm{~Hz}$ output (a) Output voltage $V_{A} 100 \mathrm{~Hz}$ (b) Output current i_A $100 \mathrm{~Hz}$

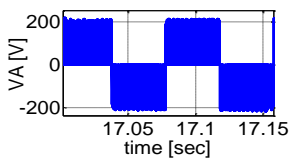

(a)

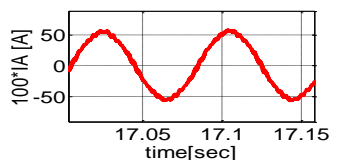

(b)

Figure 1. Simulation results for $12.5 \mathrm{~Hz}$ output (a)output voltage V_A $12.5 \mathrm{~Hz}$ (b) Output current i_A $12.5 \mathrm{~Hz}$

\section{EXPERIMENTAL RESULTS}

Experimental results were performed using DSP1104, for a MC interfaced $50 \mathrm{~Hz}$ three-phase supply with an isolated $\mathrm{R}-\mathrm{L}$ load $(\mathrm{R}=144 \Omega, \mathrm{L}=0.25 \mathrm{H})$ will be presented with switching time $=0.0002$ sec. The experimentalresults showed that the THD of output voltage is reduced with the modified algorithm and ultra modified algorithms where Figure 19 shows THD for output voltage and current with conventional algorithm, Figure 20 shows the THD with modified algorithm and Figure 21 shows experimental results for output voltage and current with the proposed algorithm which have the loer Value for THD. Figure 22 shows experimental results for an output frequency of $100 \mathrm{~Hz}$, Figure 22 (a) shows $100 \mathrm{~Hz}$ output voltage, Figure 22(b) shows $100 \mathrm{~Hz}$ output current, Figure 23 shows experimental results for an output frequency of $12.5 \mathrm{~Hz}$.

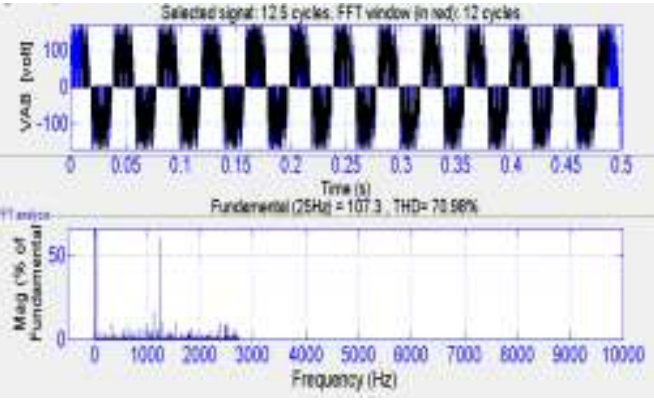

(a)

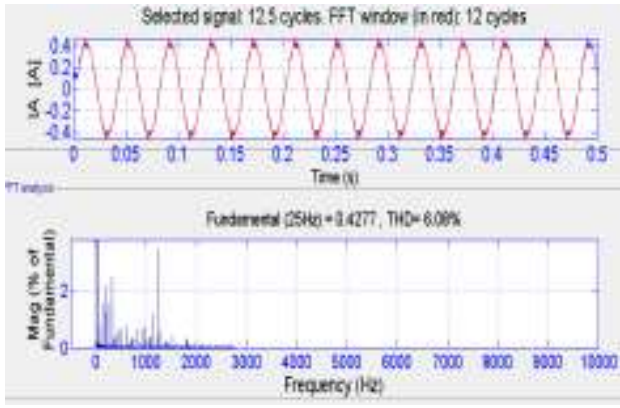

(b)

Figure 19. Experimental results for THD for $25 \mathrm{~Hz}$ (a) Output voltage,(b) Output current for conventional symmetric sequence algorithm

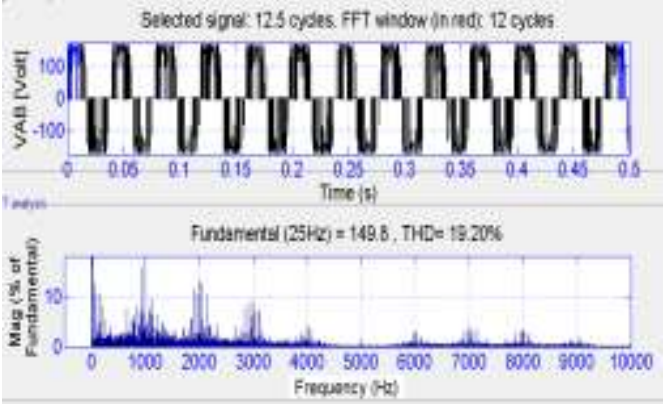

(a)
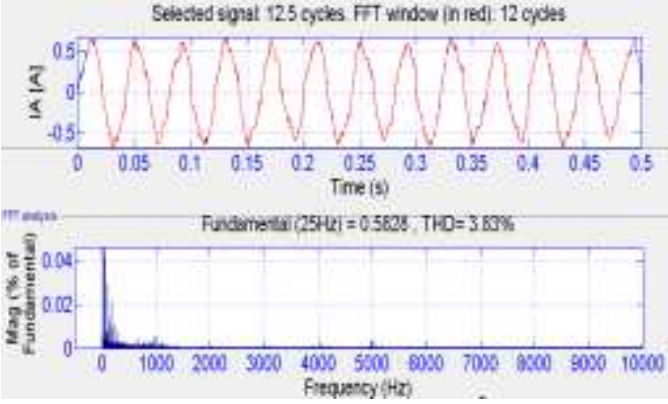

(b)

Figure 20. Experimental results for THD for $25 \mathrm{~Hz}$ (a) Output voltage,(b) Output current for modified symmetric sequence algorithm 


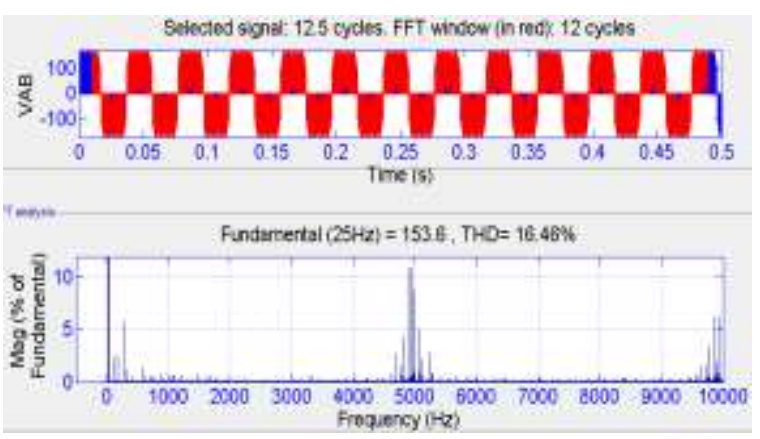

(a)
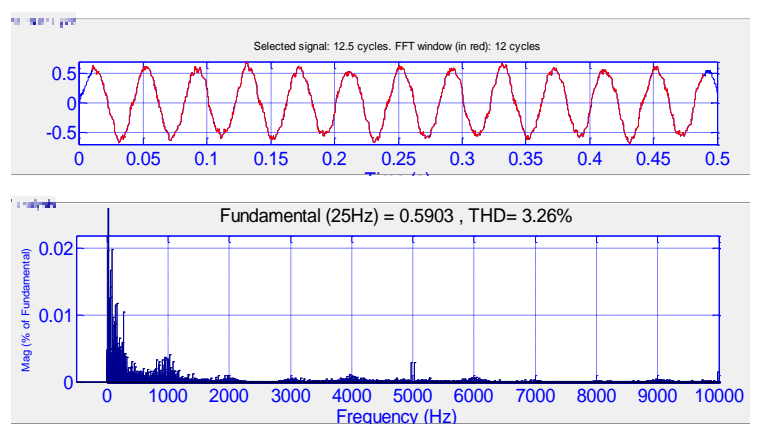

(b)

Figure 21. Experimental results for THD for $25 \mathrm{~Hz}$ (a) Output voltage,(b) Output current for ultra-modified symmetric sequence algorithm

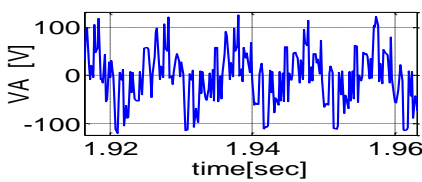

(a) Output voltage $V_{A} 100 \mathrm{~Hz}$

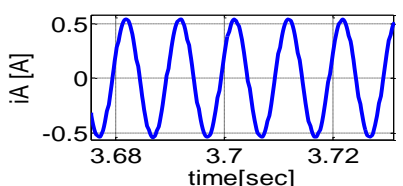

(b) Output current $i_{A} 100 \mathrm{~Hz}$

Figure 22. Experimental results for $100 \mathrm{~Hz}$ output

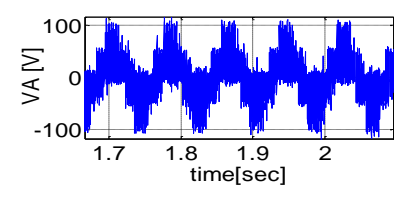

(a) Output voltage $V_{A} 12.5 \mathrm{~Hz}$

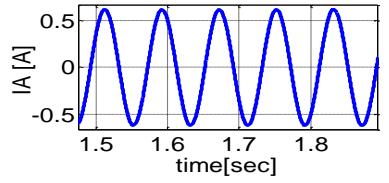

(b) Output current $i_{A} 12.5 \mathrm{~Hz}$

Figure 23. Experimental results for $12.5 \mathrm{~Hz}$ output

\section{CONCLUSION}

In this paper, an ultra- modified symmetric sequence algorithm of space vector modulation of matrix converter is introduced which overcome the drawbacks of the modified algorithm, where it reduces both THD of output voltage and output current. The MC provides a wide range of output frequency, so it can be used for high speed application, and this is the advantage of MC compared to cycloconverter. The angle between input voltage and input current of MC can be controlled and unity input displacement factor is achieved. The analysis of indirect space vector modulation was introduced, in addition to introducing how to transform from indirect MC to direct one. The simulation and experimental results were displayed which gives a presics proof for the propose algorithm.

\section{REFERENCES}

[1] Pawel Szczesniak, "A comparison between two average modelling techniques of AC-AC power converters," IJPEDS, vol. 6, no. 1, March 2015

[2] N. Lavanya, M. Venu Gopala Rao"Control of Indirect Matrix Converter by Using Improved SVM Method," International Journal of Power Electronics and Drive System (IJPEDS) Vol. 6, No. 2, June 2015, pp. 370 375

[3] P. S. Prasad, A. B. V. S. Kumar, and G. S. Rao, "Induction motor speed control by carrier modulation based matrix converter," in 2016 International Conference on Signal Processing, Communication, Power and Embedded System (SCOPES), 2016, pp. 1176-1180.

[4] P. S. Prasad, A. B. V. S. Kumar and G. S. Rao, "Induction motor speed control by carrier modulation based matrix converter," 2016 International Conference on Signal Processing, Communication, Power and Embedded System (SCOPES), Paralakhemundi, 2016, pp. 1176-1180. 
[5] F. L. Luo and Z. Y. Pan, "Sub-Envelope Modulation Method to Reduce Total Harmonic Distortion of AC/AC Matrix Converters," 2006 1ST IEEE Conference on Industrial Electronics and Applications, Singapore, 2006, pp. 1-7.

[6] D. Xiao and M. F. Rahman, "A modified direct torque control for a matrix converter-fed interior permanent magnet synchronous machine drive," 2006 37th IEEE Power Electronics Specialists Conference, Jeju, 2006, pp. 1-7.

[7] B. Wang and E. Sherif, "Spectral Analysis of Matrix Converters Based on 3-D Fourier Integral," in IEEE Transactions on Power Electronics, vol. 28, no. 1, pp. 19-25, Jan. 2013.

[8] J. Saha, A. Ayad, and R. Kennel, "Direct model predictive current control for matrix converters," in 2017 International Conference on Nascent Technologies in Engineering (ICNTE), 2017, pp. 1-5.

[9] L. Gyugyi and B. R. Pelly, " Static Power Frequency Changers: Theory, Performance, and App1ication," IEEE Trans. Antennas Propagat, 1976.

[10] M. Venturini and A. Alesina, "The generalised transformer: A new bidirectional, sinusoidal waveform frequency converter with continuously adjustable input power factor," 1980 IEEE Power Electronics Specialists Conference, Atlanta, Georgia, USA, 1980, pp. 242-252.

[11] M. A. M. A. Moftah, G. E. A. Taha and E. A. Ibrahim, "Active power filter for variable-speed wind turbine PMSG interfaced to grid and non-linear load via three phase matrix converter," 2016 Eighteenth International Middle East Power Systems Conference (MEPCON), Cairo, 2016, pp. 1013-1019.

[12] K. B. Tawfiq, A. F. Abdou, E. E. El-Kholy, and S. S. Shokralla, "A modified space vector modulation algorithm for a matrix converter with lower total harmonic distortion," in 2016 IEEE 59th International Midwest Symposium on Circuits and Systems (MWSCAS), 2016, pp. 1-4.

[13] S. M. Dabour and E. M. Rashad, "Analysis and implementation of space-vector-modulated three-phase matrix converter," in IET Power Electronics, vol. 5, no. 8, pp. 1374-1378, September 2012.

[14] S. M. Dabour, S. M. Allam and E. M. Rashad, "Indirect space-vector PWM technique for three to nine phase matrix converters," 2015 IEEE 8th GCC Conference \& Exhibition, Muscat, 2015, pp. 1-6.

[15] A. A. Amin, K. B. Tawfiq, H. Youssef and E. E. EL-Kholy, "Performance analysis of inverter fed from wind energy system," 2016 Eighteenth International Middle East Power Systems Conference (MEPCON), Cairo, 2016, pp. 512-516.

\section{BIOGRAPHIES OF AUTHORS}
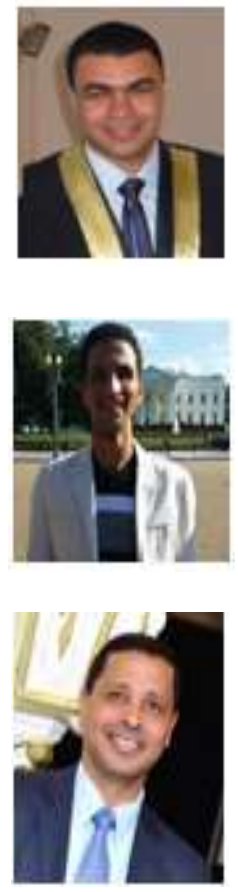

Kotb B. Tawfiq was born in Menoufia, Egypt in 1990. He received his BSc and MSc degrees in electrical engineering from the Faculty of Engineering, Menoufia University in 2013 and 2016 respectively. $\mathrm{He}$ is assistant lecturer at Electrical Engineering Department, Faculty of Engineering, Menoufia University. His main field of interest includes Power Electronics, Matrix converters and Renewable Energy. His interest also extended to Real-Time control using DSP, Fuzzy application in Power Electronics, Elect-rical machines drives and PLC. He is a regular reviewer for couple of international journal and conferences

Arafa S. Mansour was born in Cairo, Egypt in 1983. He received his BSc, MSc and PhD degrees in electrical engineering from the Faculty of Engineering, Menoufia University . Currently, he is lecturer at the Faculty of Engineering, Menoufia University, Egypt. His research interests include power electronics, renewable energy, distributed generation, smart grids, electrical machines, voltage stability, analog and digital control applications, Microcontroller and PLC

E. E. El-Kholy was born in Menoufia, Egypt in 1963. He received his BSc, MSc and PhD degrees in electrical engineering from the Faculty of Engineering, Menoufia University in 1986, 1992 and 1996 respectively. He is the Head of Electrical Engineering Department, Faculty of Engineering, Menoufia University. His main field of interest includes Power Electronics, AC/DC drives control techniques, Active Rectifiers, Active Filters, Microgrids and Renewable Energy. His interest also extended to Real-Time control using DSP, Fuzzy application in Power Electronics. 